\title{
Risk Analysis for Mega Shopping Mall Projects in Egypt
}

\author{
Samer Ezeldin and Hesham H. Ibrahim \\ Department of Construction and Architectural Engineering, American University of Caro, New Cairo 11835, Egypt
}

\begin{abstract}
Mega shopping mall projects have seen dramatic growth and great development in recent years in Egypt. Many new mega shopping mall projects are under construction and expecting to start working in the few coming years. In the absence of researches studying the Egyptian mega shopping mall projects, this study tries to highlight the most critical risks that face these projects and the associated most effective response methods to be employed. The scope covers the analysis from different perspectives by including owners/developers, designers, consultants, project managers, and contractors that have previous experience in large-scale projects such as shopping mall projects. In this study, 30 construction project risks are classified into six main categories according to their type and 150 risk mitigation/elimination measures are introduced to overcome the impact of risks under each of these risk categories. The results reveal that the main risk category that faces the mega shopping mall projects in Egypt is the one including the financial risk factors. The most critical risk factor that faces these projects is the financial ability of the client. These results are similar to findings by previous researches conducted for large projects in other countries.
\end{abstract}

Key words: Mega shopping mall projects, commercial projects, critical risks, risk mitigation/elimination measures.

\section{Introduction}

MSM (mega shopping mall) projects have seen dramatic growth and great development in recent years in Egypt. For example, the GLA (gross leasable area) within great Cairo increased from $578,000 \mathrm{~m}^{2}$ in 2010 to around 1 million square meters in the first quarter of 2014, as stated by the real estate investment and advisory firm Jones Lang LaSalle in its latest report [1]. In addition, many new MSM projects are under construction and expecting to start working in the few coming years. That dramatic increase reflects the importance and the potential investment in these types of projects. Shopping mall projects have special characters such as: exclusive locations, strong financial abilities, unique designs to be able to compete with the others, multi-tenant with different requirements, changing needs, high projects' costs, and tight time schedules. All these factors generate a new risk value and risk criticality and severity for other risks related to these projects. Therefore, in the absence of researches studying the Egyptian MSM projects, the need for a

Corresponding author: Samer Ezeldin, Ph.D., research field: construction engineering. E-mail: aezeldin@aucegypt.edu. detailed study that addresses the risk associated with such projects in Egypt is very important and valuable.

The aim of this research is to try to highlight the most critical risks that face MSM projects in Egypt and the associated most effective response methods to be employed.

Though other researchers have discussed the research topic before, it is considered to be innovative for three reasons. The first reason is its applicability to the Egyptian construction industry. The second reason is that it tries to extract detailed data from practitioners from the Egyptian construction industry in different roles concerning two aspects of risk management, namely: risk identification and risk response, whereas other researchers who addressed the Egyptian construction industry tackled only one of the aforementioned risk management activities. The third reason is the time frame in which this research has been conducted during the first half of the year 2014 revealing the different roles' perception of risks and their response methods after many variables and crises affected the industry, mainly the Egyptian revolution and the political upheaval stemming from it in early 2011 and their consequences during the last 3 years. 


\section{Methodology}

In order to acquire a comprehensive background about the aspects of this study, an extensive literature review was conducted into risk factor issues globally as related to the Egyptian construction industry. Such extensive review culminated into the development of a comprehensive questionnaire that was, using customized interviews, administered to qualified practitioners in the Egyptian construction industry.

The data collected from these experts, having different roles in these projects, are then statistically processed for the purpose of generalizing its findings. A comprehensive study was conducted through direct interviews with experts and by using the literature review to define the criteria of the target population, sample size, and the sample procedures that match with the target shopping mall projects in Egypt.

Verification was held for the top ranked critical risks that was obtained through the questionnaire by comparing the nature of construction risks encountered in the Egyptian market to the data extracted from literature for other national and international construction markets. Moreover, the study findings are incorporated into an easy-to-use Excel spreadsheet to aid practitioners in preparing effective risk management for such projects.

\section{Questionnaire Content}

The questionnaire content is finalized after conducting an extensive review of the relevant literature and consulting qualified and competent practitioners working in the field of construction. In order to simplify the assessment of the most critical risks, it was decided to classify the risks according to their types, as suggested by several practitioners. Hence, six main risk categories, according to literature, were set:

(1) construction and design risks;

(2) financial and economic risks;

(3) political/government risks;

(4) client-generated risks;
(5) subcontractors-generated risks;

(6) miscellaneous risks.

A list of 30 risks were identified for the research's questionnaire as shown in Table 1. After an extensive literature review, a total of 150 possible response methods were also identified. The response methods were distributed among four response techniques, namely: (1) elimination; (2) transfer; (3) reduction; (4) retention.

\section{Target Population}

The members of the target population are the entities having major yet different roles in MSM projects, namely: owners/developers, project managers, designers, consultants, and contractors. Accordingly, the target population includes:

- large scale domestic contractors registered under Class "One" of building and complementary work categories according to the Egyptian Federation for Construction and Building Contractors;

- international or multinational contractors currently working in Egypt;

- consultants and design firms registered as Class "A" according to the Egyptian Engineers Syndicate;

- national or international project management firms working in the Egyptian construction industry having previous large scale shopping mall projects in Egypt;

- reputable owners/developers that have large shopping mall projects working in Egypt or who are currently building such large projects.

The estimated number of MSM projects, either existing or still under construction in Egypt, is currently about 40 projects. Based on the above, the size of the target population according to the aforementioned criteria for different roles is approximately equal to: 40 projects $\times 5$ different roles $=200$ companies in different roles.

\section{Sample Size}

Dornyei [2] presented the following guidelines to 
Table 1 Risk factors included in the questionnaire survey.

\begin{tabular}{|c|c|c|c|}
\hline Serial & Risk code & Risk group & Risk factor \\
\hline 1 & A1 & \multirow{8}{*}{ 1. Construction and design risks } & Improper design \\
\hline 2 & $\mathrm{~A} 2$ & & Constructability \\
\hline 3 & A3 & & Improper project management \\
\hline 4 & A4 & & Site safety \\
\hline 5 & A5 & & Low construction productivity \\
\hline 6 & A6 & & Defective work \\
\hline 7 & A7 & & Resources unavailability \\
\hline 8 & A8 & & Defective material \\
\hline 9 & $\mathrm{~B} 1$ & \multirow{4}{*}{ 2. Financial and economic risks } & Foreign exchange and convertibility \\
\hline 10 & B2 & & Cash shortage \\
\hline 11 & B3 & & Inflation and interest rates \\
\hline 12 & B4 & & Competition \\
\hline 13 & $\mathrm{C} 1$ & \multirow{5}{*}{ 3. Political/government risks } & Political instability \\
\hline 14 & $\mathrm{C} 2$ & & Change in laws \\
\hline 15 & $\mathrm{C} 3$ & & Corruption \\
\hline 16 & $\mathrm{C} 4$ & & Approvals and permits \\
\hline 17 & $\mathrm{C} 5$ & & Expropriation \\
\hline$\overline{18}$ & D1 & \multirow{4}{*}{ 4. Client-generated risks } & Financial ability \\
\hline 19 & D2 & & Changing needs \\
\hline 20 & D3 & & Claims \\
\hline 21 & D4 & & Possession of site \\
\hline 22 & E1 & \multirow{3}{*}{ 5. Subcontractors-generated risks } & Technical qualifications \\
\hline 23 & E2 & & Financial ability \\
\hline 24 & E3 & & Variation of bids \\
\hline$\overline{25}$ & F1 & \multirow{6}{*}{ 6. Miscellaneous risks } & Differing site conditions \\
\hline 26 & $\mathrm{~F} 2$ & & Physical damages \\
\hline 27 & F3 & & Force majeure \\
\hline 28 & $\mathrm{~F} 4$ & & Partnership \\
\hline 29 & F5 & & Environmental protection \\
\hline 30 & F6 & & Legal risks \\
\hline
\end{tabular}

aid researchers in specifying the minimum sample size:

- A range of $1 \% \sim 10 \%$ of the population is usually mentioned as the magic sampling fraction depends on how careful the selection has been;

- From a statistical point of view, to obtain a normal distribution of the samples, theoreticians have agreed that a minimum sample size of $25 \sim 30$ samples should be obtained.

As indicated by Dornyei [3], the magic sample fraction is maximum $10 \%$ of the population. The target population as indicated above is equal to: 40 projects $\times$ 5 different roles $=200$ companies in different roles. So, a sample size of at least 20 companies in different roles is required.
Assuming an average of two replies from each company means that the number of qualified replies should be around 40 responses, which would satisfy the minimum requirements for statistical representation.

For this research, 65 questionnaires were sent out to different role companies and expert engineers. Forty-four successful responses were received within the pre-defined receiving period and were considered as an acceptable sample size for this research.

\section{Statistical Analysis}

The standard method of analyzing quantitative questionnaire data is by means of submitting them to 
various statistical procedures. These procedures are categorized under two broad categories: descriptive statistics and inferential statistics.

\subsection{Descriptive Statistics}

Descriptive statistics are used to summarize the data collected and present them in smaller space and easier to read and interpret format. The set-forth descriptive statistics procedures are performed on the different multi-item scales and each single item of this research questionnaire: mean, range, mode, median, standard deviation, and skewness. Further, ranking the risk factors using the mean value in a descending order in accordance to:

- the probability of occurrence of defined risks $(P)$;

- the impact of occurrence of defined risks $(I)$;

- the multiplication (criticality) of the two aforementioned variables: $R=P \cdot I$;

- the various risks' respective mitigation measures.

\subsection{Inferential Statistics}

Inferential statistics are used to measure the statistical significance of the results obtained from the descriptive statistics if they are powerful enough to indicate a more generalized phenomenon. In other words, inferential statistics are used to enable the researcher to generalize the results obtained from the statistical analysis performed on the sample data over the whole population. The inferential statistics procedure used in this research is the ANOVA (analysis of variance), which is performed to specify the variance of the results obtained between different roles, i.e., owners group, designers group, consultants group, project managers group and contractors group. The significance tests are conducted at a 5\% level of significance using an $\mathrm{F}$ distribution.

\section{Date Collection and Analysis}

\subsection{Number of Years of Work Experience}

The number of years of experience of the respondents to the questionnaire should indicate important information as to the number of construction project risks they have been exposed to and how they are aware of the associated response methods. About $43 \%$ (19 participants) of the respondents have more than 20 years of experience, which indicates that the input data of the research is adequately reliable in terms of experience of the respondents.

\subsection{Participants' Roles}

In general, the construction industry is characterized by the multiplicity of different involved participants such as owners, consultant and contractor, etc. and every party has his own vision that may have some differences from the others. As noted before, this research is aimed to examine the risks as a general within all participants in the Egyptian construction industry. About $23 \%$ (10 participants) of the respondents are representing the owners group. Around $14 \%$ (six participants) of the respondents are representing the designers group. Almost 18\% (eight participants) of the respondents are representing the consultants group. Finally, 20\% (nine participants) of the respondents are representing the project managers group and 25\% (11 participants) of the respondents are representing the contractors group. These percentages indicate that the input data of the research are adequately reliable in terms of the roles of the respondents.

\section{Criticality of Construction Risks}

One of the main goals of this research is to achieve a list of the most critical risks that face MSM projects in the Egyptian construction industry through analyzing the data collected via the questionnaire survey.

The risk criticality (severity) is calculated by multiplying the probability of a defined risk to occur with the impact it may cause. Table 2 lists the top 10 risks based on the criticality factor and according to their means as well as revealing their median, mode, 
standard deviation, skewness and range.

The risk factor D1 "financial ability" has the most critical score 3.52 that reflects very important issue related to MSM projects that require strong financial ability from the client to complete such expensive projects. The complete ranking list of the 30 risks are indicated in Ibrahim (2014).

\section{Risk Response Methods Effectiveness}

The second objective of this study is to identify the risk response methods (mitigation methods) related to MSM projects in the construction industry in Egypt and their effectiveness. As previously mentioned, the questionnaire survey is divided into six subsections, which collectively includes 150 response methods for the 30 different construction project risks as listed in Table 3. The complete listing of the 150 risk response methods is listed in Ibrahim [4]. A scale of effectiveness from 1 (not effective) to 5 (extremely effective) was provided for the participants' selection.

The 150 response methods are divided among the four response techniques, namely: elimination, transfer, reduction and retention. Descriptive statistical analysis was performed on the data collected from the respondents concerning the risk response method to obtain the mean, median, mode, standard deviation, skewness and range values. The analysis revealed that the reduction technique is the most popular one within all risk groups. The second tool is the elimination technique within the different risk groups. The complete set of response methods to their respective risks can be found in Ibrahim [4].

\section{Comparison with Previous Studies in Egypt}

Orabi in 2003 conducted a study on the construction risks for Egypt from the contractor point of view. Table 4 shows that the most critical risk factors (top 10 most critical risks) in both researches are almost the same with a slight difference in risks' orders. Financial ability of the client risk is the most critical risk in both studies. Each study identifies the same seven risks in the top 10 list of the other study. Only three risk factors are different within the top 10 risk factors that relate to

Table 2 Ranking of the severity of risks according to their means and standard deviations.

\begin{tabular}{llllllllll}
\hline Rank & Risk code & Mean & Mode & Median & Min & Max & Range & Standard deviation & Skewness \\
\hline 1 & D1 & 3.523 & 4.000 & 3.200 & 1.600 & 5.000 & 3.400 & 0.954 & 0.017 \\
2 & A1 & 3.300 & 3.200 & 3.200 & 1.200 & 5.000 & 3.800 & 1.104 & 0.009 \\
3 & B2 & 3.268 & 4.000 & 3.600 & 0.800 & 5.000 & 4.200 & 1.202 & -0.222 \\
4 & D2 & 3.200 & 3.200 & 3.200 & 0.800 & 5.000 & 4.200 & 0.948 & 0.161 \\
5 & C4 & 3.082 & 4.000 & 3.200 & 1.200 & 5.000 & 3.800 & 0.942 & -0.096 \\
6 & A3 & 3.068 & 2.400 & 3.000 & 0.800 & 5.000 & 4.200 & 1.064 & 0.133 \\
7 & D3 & 3.005 & 2.400 & 3.100 & 1.000 & 5.000 & 4.000 & 1.120 & 0.263 \\
8 & B1 & 2.936 & 3.200 & 3.200 & 0.800 & 5.000 & 4.200 & 1.236 & 0.144 \\
9 & C1 & 2.855 & 3.200 & 2.700 & 0.200 & 5.000 & 4.800 & 1.313 & 0.260 \\
10 & A7 & 2.850 & 5.000 & 2.700 & 0.200 & 5.000 & 4.800 & 1.300 & 0.204 \\
\hline
\end{tabular}

Table 3 Number of risks within different groups and the number of associated response measures.

\begin{tabular}{lllcll}
\hline Serial & Code & List of groups & No. of risks & Response codes & No. of mitigation methods \\
\hline 1 & Group A & Construction and design risks & 8 & From A11 to A85 & 43 \\
2 & Group B & Financial and economic risks & 4 & From B11 to B45 & 23 \\
3 & Group C & Political/government risks & 5 & From C11 to C54 & 29 \\
4 & Group D & Client-generated risks & 4 & From D11 to D44 & 17 \\
5 & Group E & Subcontractors-generated risks & 3 & From E11 to E34 & 14 \\
6 & Group F & Miscellaneous risks & 6 & From F11 to F64 & 24 \\
\hline Total & & & 30 & & 150 \\
\hline
\end{tabular}


Table 4 Comparison of this research's results with the results of Orabi's [5] research.

\begin{tabular}{lllll}
\hline Serial & Risk description & Risk code & Ibrahim [4] & Orabi [5] \\
\hline 1 & Financial ability & D1 & 1 & 1 \\
2 & Improper design & A1 & 2 & 6 \\
3 & Cash shortage & B2 & 3 & 4 \\
4 & Changing needs & D2 & 4 & 24 \\
5 & Approvals and permits & C4 & 5 & 13 \\
6 & Improper project management & A3 & 6 & 2 \\
7 & Claims & D3 & 7 & 7 \\
8 & Foreign exchange and convertibility & B1 & 8 & 5 \\
9 & Political instability & C1 & 9 & 27 \\
10 & Resources unavailability & A7 & 10 & 8 \\
\hline
\end{tabular}

Table 5 Comparison of this research's results with the results of Alwan's [6] research.

\begin{tabular}{lllll}
\hline Serial & Risk description & Risk code & Ibrahim [4] & Alwan [6] \\
\hline 1 & Financial ability & D1 & 1 & 1 \\
2 & Improper design & A1 & 2 & 7 \\
3 & Cash shortage & B2 & 3 & 6 \\
4 & Changing needs & D2 & 4 & 3 \\
5 & Approvals and permits & C4 & 5 & 4 \\
6 & Improper project management & A3 & 6 & 13 \\
7 & Claims & D3 & 7 & - \\
8 & Foreign exchange and convertibility & B1 & 8 & 14 \\
9 & Political instability & C1 & 9 & 9 \\
10 & Resources unavailability & A7 & 10 & 10 \\
\hline
\end{tabular}

the changing needs risk factor that can be very critical in projects such as MSM projects. Political instability risk's order is changed from 27 to 9 in this study reflecting how the country is still suffering from serious internal unrests. Approvals and permits risk is found in both studies, with the ranking much higher in this study due to the sensitive characteristics of MSM projects.

\section{Comparison with the International Construction Industries}

First, this research conducts a comparison study with another developing market that is geographically close but has a different social and economic framework, namely Sudan [6]. Table 5 shows that each study identifies six risks in the top 10 list of the other study. Only two risk factors are different within the top 10 risk factors and only one risk factor was not found in the other research. Improper project management was found less important in the Alwan [6] study and also foreign exchange and convertibility was ranked least critical in the Sudanese construction industry. Financial ability is the most critical risk in both studies reflecting the importance of this risk within the construction industry. Changing needs ranked almost the same as also the approvals and permits risks are the same. Political instability has the same ranking in both studies because both countries seem to have unrest conditions. Resources unavailability is ranked as the 10th critical risk factor in both studies that reflects the same resource problems that can be found in developing countries like Egypt and Sudan.

Second, a comparison is made with a vibrant and a quick-developing market, namely, UAE (United Arab Emirates). A study conducted by El-Sayegh [3] identifies and assesses the significant risks in the UAE construction industry and addresses their proper allocation. Data were collected through a questionnaire distributed to construction experts. A major point to be remembered when dealing with the UAE market is the 
great number of Egyptian engineers who have worked or are still working in the UAE. Table 6 shows that each study identifies three critical risks within the top 10 list of the other study but in different orders. Three risk factors in El-Sayegh's [3] study are not found in the top 10 risk factors of this study. Financial ability risk is not found in the UAE study probably because the UAE does not face such financial problems in the construction industry. Improper design is found less important in El-Sayegh's [3] study, and also foreign exchange and convertibility was ranked less critical in the UAE construction industry. Changing needs is a critical risk that reflects the existence of this risk in both studies and in both construction industries.

In an attempt to compare this study results with a major, developed market but with some social and background resemblances to the Egyptian market, China was selected. Tang et al. [7] conducted a study to report the findings of an empirical Chinese industry survey on the importance of project risks, application of risk management techniques, status of the risk management system, and the barriers to risk management, which were perceived by the main project participants. Table 7 shows that each study identifies five risks in the top 10 list of the other study. Three risk factors in the Tang et al. [7] study are less in ranking within the top 10 risk factors and two risk factors are not found in the other research. The top three risk factors are existing in both studies with slight difference in the ranking order. Changing needs risk is not found in Tang et al.'s [7] study. Also, political instability is not found. Claims risk is found less important in the Tang's study, and also foreign exchange and convertibility is ranked less critical in the Chinese construction industry. Moreover, the resource unavailability risk is less critical in the Chinese construction industry. Approvals and permits risk and improper project management risks are found in both studies with slight difference in the ranking position.

Table 6 Comparison of this research's results with the results of El-Sayegh's [3] research.

\begin{tabular}{lllll}
\hline Serial & Risk description & Risk code & Ibrahim [4] & El-Sayegh [3] \\
\hline 1 & Financial ability & D1 & 1 & - \\
2 & Improper design & A1 & 2 & 16 \\
3 & Cash shortage & B2 & 3 & 14 \\
4 & Changing needs & D2 & 4 & 5 \\
5 & Approvals and permits & C4 & 5 & 8 \\
6 & Improper project management & A3 & 6 & - \\
7 & Claims & D3 & 7 & 12 \\
8 & Foreign exchange and convertibility & B1 & 8 & 32 \\
9 & Political instability & C1 & 9 & - \\
10 & Resources unavailability & A7 & 10 & 7 \\
\hline
\end{tabular}

Table 7 Comparison of this research's results with the results of Tang et al. [7] research.

\begin{tabular}{lllll}
\hline Serial & Risk description & Risk code & Ibrahim [4] & Tang et al. [7] \\
\hline 1 & Financial ability & D1 & 1 & 5 \\
2 & Improper design & A1 & 2 & 4 \\
3 & Cash shortage & B2 & 3 & 5 \\
4 & Changing needs & D2 & 4 & - \\
5 & Approvals and permits & C4 & 5 & 9 \\
6 & Improper project management & A3 & 6 & 9 \\
7 & Claims & D3 & 7 & 11 \\
8 & Foreign exchange and convertibility & B1 & 8 & 21 \\
9 & Political instability & C1 & 9 & - \\
10 & Resources unavailability & A7 & 10 & 15 \\
\hline
\end{tabular}




\section{Conclusions}

This section presents an overview of this research and a summing up of its findings. The most critical risks encountered in different perspectives by including owners/developers, designers, consultants, project managers, and contractors that have previous experience in large-scale projects such as shopping mall projects in the Egyptian construction industry in a descending criticality order are:

- financial ability: the client is unable to finance the project—Risk D1;

- improper design: incomplete design scope, design changes, defective design, errors and omissions, or inadequate specifications-Risk A1;

- cash shortage: unavailability of sufficient in-house cash flow or of funds from owner-Risk B2;

- changing needs: client expectations from the project are changed from those stated in the project through change orders-Risk D2;

- approvals and permits: delay or refusal of project approval and permit by government or authority—Risk C4.

These results indicate that in mega projects such as shopping mall projects in the Egyptian construction industry, the financial risks are the most critical risks that endanger these projects. Changing needs due to the existence of multi-tenants in mega projects are also considered as within the most critical risks in such types of projects. Due to the political instability after the January 25, 2011, the political instability risk is considered a critical risk that can affect the project's completion.

Risk transfer and retention techniques were found to be unsuitable for eliminating and/or mitigating the impact of such risks as the financial and economic risks and subcontractor-generated risks. Using contractual measures was the key response method that was perceived by all different participants as the most effective method to eliminate/mitigate the effect of most of the risks considered in this research. In addition to these contractual measures, dealing with reputable owners is also a very effective risk response method that did well in eliminating/mitigating the impact of different risks especially those that have something to do with the financing of shopping mall projects.

\section{References}

[1] LaSalle, J. L. 2014. Cairo Real Estate Market Overview-Q2 2014. Jones Lang LaSalle report. Accessed January 6, 2014. http://www.jll-mena.com/mena/en-gb/research/295/cairoreal-estate-market-overview-q2-2014.

[2] Dornyei, Z. 2003. Questionnaires in Second Language Research: Construction, Administration, and Processing. New Jersey: Lawrence Erlbaum Associates.

[3] El-Sayegh, S. 2008. "Risk Assessment and Allocation in the UAE Construction Industry." International Journal of Project Management 26: 431-8.

[4] Ibrahim, H. 2014. "Risk Analysis for Mega Commercial Projects." M.Sc. thesis, The American University in Cairo.

[5] Orabi, O. 2003. "Risk Identification and Response Methods in the Egyptian Construction Industry: Views of Large Scale Contractors." M.Sc. thesis, The American University in Cairo.

[6] Alwan, Z. 2006. "Risk Identification, Classification and Response Methods in the Sudanese Construction Industry." M.Sc. thesis, The American University in Cairo.

[7] Tang, W., Qiang, M., Duffield, C., Young, D., and Lu, Y. 2007. "Risk Management in the Chinese Construction Industry." Construction Engineering and Management ASCE (American Society of Civil Engineers) 133: 944-56. 